\title{
Lasers and applications as a motivation program for high school students
}

\section{Lionel Canioni, Alain Fleury, Laurent Sarger}

Lionel Canioni, Alain Fleury, Laurent Sarger, "Lasers and applications as a motivation program for high school students," Proc. SPIE 9663, Eighth International Topical Meeting on Education and Training in Optics and Photonics, 96631X (6 October 2003); doi: 10.1117/12.2208502

SPIE Event: Eighth International Topical Meeting on Education and Training in Optics and Photonics, 2003, Tucson, Arizona, United States 


\title{
LASERS and Applications As a motivation program for high school students
}

\author{
Lionel CANIONI, Alain FLEURY and Laurent SARGER \\ S.F.P- University BORDEAUX \\ 351 cours de la Liberation, 33405 TALENCE \\ Tel (33) 540006 196- Fax : (33) 540006970 \\ l.sarger@cpmoh.u-bordeaux1.fr
}

\begin{abstract}
In order to attract more high school students in the scientific and technical universities, we develop an " itinerary class room in laser technology". Based on laser hardware that fits within few small suitcases, a general and illustrated talk on laser basics is followed by various experiments by the students themselves
\end{abstract}

OCIS codes: $(000.2060 ; 000.2190 ; 000.5920)$

\section{Summary}

The diminution of the number of students in our scientific programs in Universities has obviously various origins. The image of the technology and the scientist in his lab is somehow not appealing enough for the high school student. To counteract this trend, we conceived a set of animation able to bring inside high schools some of the leading technology in photonics: namely lasers and applications.

The classical action with formal seminars to the students has to evolved towards a more technical interaction between students and instructors in a concept recently introduced as " La main à la pate" i.e. "Kitchen Physics"

First, the availability of mini components - lasers and detectors- greatly ease the task but the price is still too high for a high school budget. We designed a set of rugged experiments, these fit into suitcases (the whole set can fit into a van) to illustrate laser basics and applications. The quantity of experiments enables us to entertain a class of 20 to 25 students for 3 hours. Three different themes are developed always illustrating the laser as a powerful tool for applications. This is done by playing around with various kits of lasers (Helium-Neon gas laser, diode lasers and micro YAG lasers with conversion frequency chain), optical fibers and detectors as web cams and minispectrograms. Unique capabilities of the lasers in terms of beam shape, tunabilty, spectral and spatial power density, are especially pointed out of each experiments. Here, we are putting only little emphasis on the alleged monochromaticity as usually done, but rather on the flexibility of the laser tool. Applications are also demonstrated and commented as barcode readers, free space communication and selective excitation for environment control.

This task is not only technical but involved a social point of view. We decide to take advantage of our students in undergraduate school as technical instructors. The small age difference with high school students certainly ease the communication and can more naturally evoke the university curricula and possibilities.

To introduce these actions, we organize a 6 months exhibit on lasers and applications into the Bordeaux science museum " CAP SCIENCES". Real world applications with various lasers systems have been presented to scholars and teachers together with the set of pedagogical experiments described here. The whole concept, "itinerary class room in laser basics" and the exhibit are now available to other mediation institution on request.

\section{Miscellaneous}

Acknowledgments, footnotes and job descriptions should not be included in the summary

This work was funded by the Conseil Regional d'Aquitaine, Fonds Europeen FEDER, C.E.A and CAP SCIENCES

Eighth International Topical Meeting on Education and Training in Optics and Photonics,

edited by Barry L. Shoop, Grover Swartzlander Jr., Proc. of SPIE Vol. 9663, 96631X

(c) 2003 SPIE, OSA, ICO · doi: 10.1117/12.2208502 